\title{
Assessment of the combined effect of heavy metals and polyaromatic hydrocarbons on the cultural plants
}

\author{
Saglara Mandzhieva ${ }^{1, *}$, Anatiliy Barakhov ${ }^{1}$, Tatiana Minkina ${ }^{1}$, Victor Chaplygin ${ }^{1}$, and \\ Svetlana Sushkova ${ }^{1}$ \\ ${ }^{1}$ Southern Federal University, 194/1, prosp. Stachki, 344090, Rostov-on-Don, Russia
}

\begin{abstract}
The environmental contamination by heavy metals (HM) and polycyclic aromatic hydrocarbons (PAH) is often due to exposure to complex sources of industrial and agricultural activities. The aim of the work is to evaluate the combined effect of $\mathrm{CuO}$ and benzo(a)pyrene ( $\mathrm{BaP})$ on the state of spring barley plants. It was established that the soil combined pollution by $\mathrm{CuO}$ and $\mathrm{BaP}$ has a negative effect on all morphobiometric parameters of barley. The most sensitive indicators of combined contamination are the length of the roots, the mass of 1000 grains and the yield of barley.
\end{abstract}

\section{Introduction}

Combined contamination of soil with heavy metals (HM) and benzo(a)pyrene (BaP) in most cases is characteristic of anthropogenic impact. The $\mathrm{BaP}$ is the most common representative of polycyclic aromatic hydrocarbons (PAHs), which is subject to mandatory control in all countries of the world and is an indicator of contamination with these compounds. The combined release of HM and PAHs into the environment is often due to the impact of complex industrial and agricultural sources emitting a whole complex of pollutants. The presence of hydrophobic organic pollutants, such as PAHs, often accompanies HM contamination in the soils of industrial areas: tailing facilities, thermal power plants, oil refineries, etc. $[1,2,3]$. The need to study the mechanism for transformation and degradation of hydrophobic organic compounds in soils contaminated with $\mathrm{HM}$ is due to the peculiarities of $\mathrm{HM}$ absorption by soils under combined contamination with organic pollutants, which depend on intermolecular interactions of toxicants [4].

Combined soil contamination with TM and PAHs poses a particular risk to the environment and human health: it aggravates and deteriorates the ecological state of soils, increases the mutual toxicity of organic and inorganic pollutants, and can enhance their bioavailability $[5,6,7,8]$. However, there are few works on the combined contamination with HM and PAHs $[9,10]$. The problem of HM compound transformation in soil in the presence of organic pollutants is currently insufficiently studied. Available results are often contradictory and require further research. Under combined contamination pollutants can

${ }^{*}$ Corresponding author: msaglara@mail.ru 
affect simultaneous absorption of HMs and PAHs by plants, have a direct effect on microorganisms and a wide range of microbiological processes, as well as produce direct and indirect effects on the degradation of organic pollutants [3]. In case heavily polluted soil the negative influence of $\mathrm{HM}$, in particular $\mathrm{Cu}$, on the organic pollutant destruction needs to be taken into account [7]. The presence of PAHs, as a rule, increased the concentration of $\mathrm{Cu}$ in aqueous extracts; therefore, more attention should be paid to the potential risk of HM accumulation for the soil ecosystem. A concomitant effect of an increase in HM concentration on the sorption of phenanthrene condensed on surface soil particles and sorbed by organic carbon, which had a higher sorption affinity for PAHs, has been established [7].

\section{Materials and Methods}

To assess the combined effect of TM and PAHs on the state of plants (Hordeum sativum distichum), a model experiment was launched. The upper layer $(0-20 \mathrm{~cm})$ of Haplic Chernozem from specially protected natural area called "Persianovsky Preserved Steppe" that is located far from possible sources of pollution was studied. The soil properties are presented in Table 1.

Table 1. Physical and chemical properties of heavy loamy Haplic chernozem.

\begin{tabular}{|c|c|c|c|c|c|c|c|}
\hline \multirow{2}{*}{$\begin{array}{c}\text { Horizon, } \\
\text { depth in cm }\end{array}$} & \multirow{2}{*}{$\mathbf{p H}$} & Physical clay & Silt & $\begin{array}{c}\text { Organic } \\
\text { carbon } \\
\text { content }\end{array}$ & $\mathbf{C a C O}_{\mathbf{3}}$ & $\mathbf{C a}^{2+}+\mathbf{M g}^{\mathbf{2 +}}$ & $\begin{array}{c}\text { Cation } \\
\text { exchange } \\
\text { capacity }\end{array}$ \\
\cline { 2 - 8 } & & \multicolumn{5}{|c}{$\%$} & \multicolumn{2}{|c|}{$\mathrm{sM}(+) \cdot \mathrm{kg}^{-1}$} \\
\hline $\mathrm{A}, 0-20$ & 7.3 & 48.1 & 28.6 & 3.7 & 0.1 & 35.0 & 36.0 \\
\hline
\end{tabular}

The 2 litre containers with a closed drainage system were used. They were filled in with $2 \mathrm{~kg}$ of soil sifted through a 2-mm mesh sieve. Soil samples of carbonate Haplic chernozem were saturated with an aqueous $\mathrm{CuO}$ solution at doses of 300 and $2000 \mathrm{mg} / \mathrm{kg}$. The dose of $300 \mathrm{mg} / \mathrm{kg}$ of soil corresponded to the level of soil contamination in Rostov region [1]. A high level of soil pollution (up to $2000-10000 \mathrm{mg} / \mathrm{kg}$ and more) occurs near chemical enterprises, enterprises for non-ferrous metal ores extraction and processing [11]. At the same time the dose of $2000 \mathrm{mg} / \mathrm{kg} \mathrm{Cu}$ is critical for crops. The use of such a dose reveals how plants can be affected by HM. In variants with combined exposure to metal and $\mathrm{BaP}$, at a dose of 10 MPC $[12,13]$, a solution of BaP in acetonitrile $\left(219-222 * 10^{-6} \mathrm{mg} / \mathrm{kg}\right)$ was applied to the soil surface. Two-row spring barley (Hordeum sativum distichum) of the Ratnik variety was used as a test culture. The experiment was laid in triplicate.

Spring barley plants were selected in full maturity phase. Morphobiometric parameters of plants were analyzed by the method of V.V. Tserling [14]: plant height, stem length, spike length, root length, 1000-grain weight and yield. HM toxicity limits are usually determined by their effect on the plant: if the plant reduces yield or height by $5-10 \%$, HM level in the soil is considered toxic.

\section{Results and Discussion}

Morphological and anatomical changes in test plants are most noticeable when environmental conditions in the growing area deteriorate. Inhibition of the growth and development of cultivated and wild-growing plant under combined contamination has been detected by many researchers [15].

The model experiment with combined contamination demonstrated that the morphobiometric parameters of spring barley deteriorated not only in comparison with the 
control variant, but also compared to the separate introduction of $\mathrm{CuO}$ (Figure 1,2). One of the most sensitive characteristics is root length of the test plant, which decreased under combined contamination by $22 \%$ in the variant with $300 \mathrm{mg} / \mathrm{kg}$ of metal and $32 \%$ in the variant with $2000 \mathrm{mg} / \mathrm{kg}$ of metal compared to the control variant and by $15 \%$ and $27 \%$, respectively, compared to the separate introduction of $\mathrm{CuO}$. Plant height decreased by $10 \%$ and $27 \%$ compared with the control variant and by $6 \%$ and $12 \%$ compared to the separate introduction of $\mathrm{CuO}$ due to a decrease in stem height. Combined contamination contributed to a decrease in leaf length, spike height with awns and spike height without awns. However, these changes were not as pronounced as other parameters (Figure 1,2).
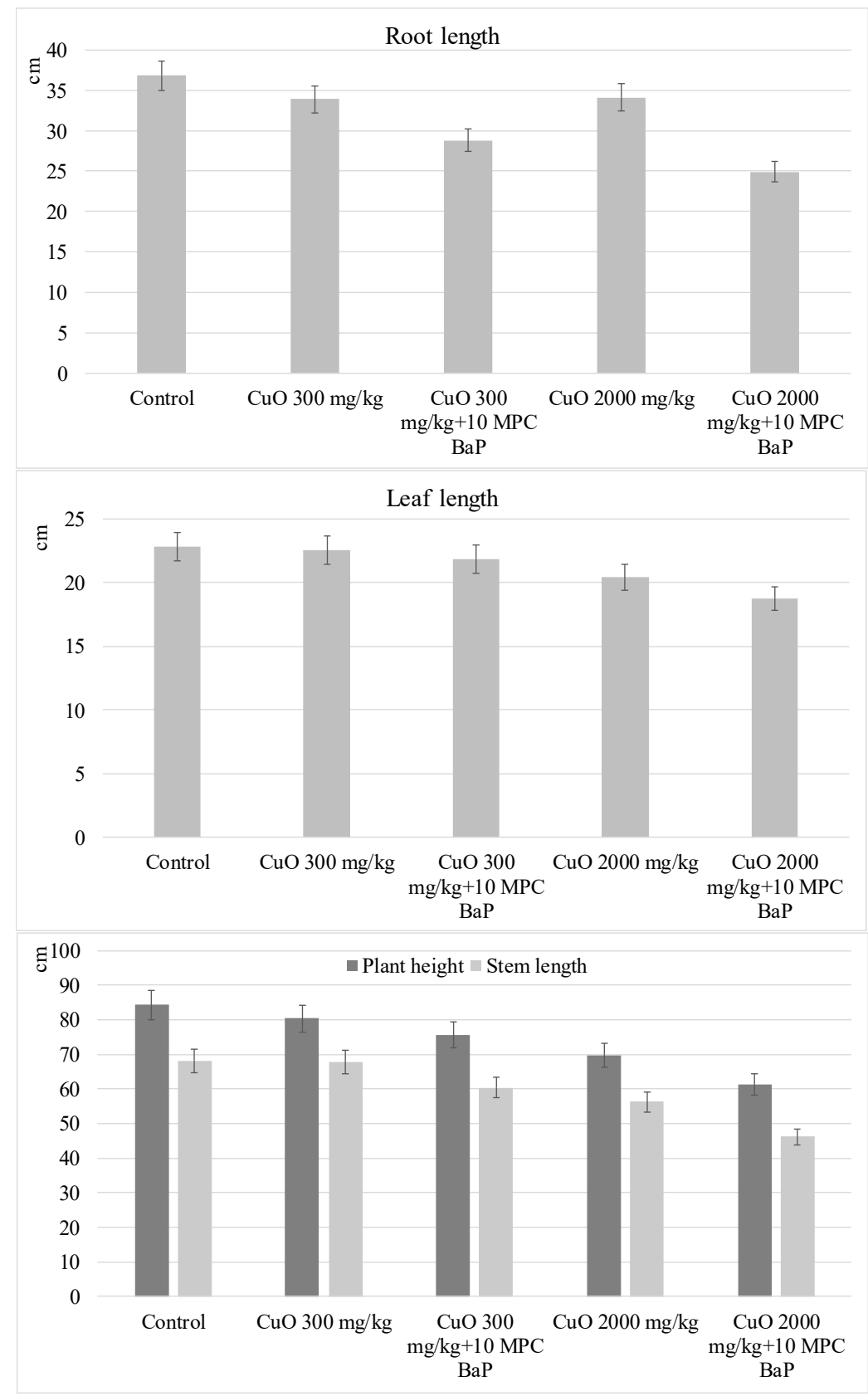
Fig. 1. Morphometric parameters of two-row spring barley (Hordeum sativum distichum) in the full maturity phase.

A significant decrease in the weight of 1000 grains was revealed in the variant of combined contamination with $\mathrm{BaP}$ and $\mathrm{CuO}$ at a dose of $10,000 \mathrm{mg} / \mathrm{kg}$ by $39 \%$ compared to the control variant and by $25 \%$ compared to separate $\mathrm{CuO}$ introduction (Figure 1). One of the consequences of reducing 1000-grains weight was a significant decrease in yield: by $31 \%$ and $56 \%$ compared to the control variant and by $14 \%$ and $22 \%$ compared to the separate introduction of $\mathrm{CuO}$ in the variants with 300 and 2,000 mg/kg CuO, respectively.

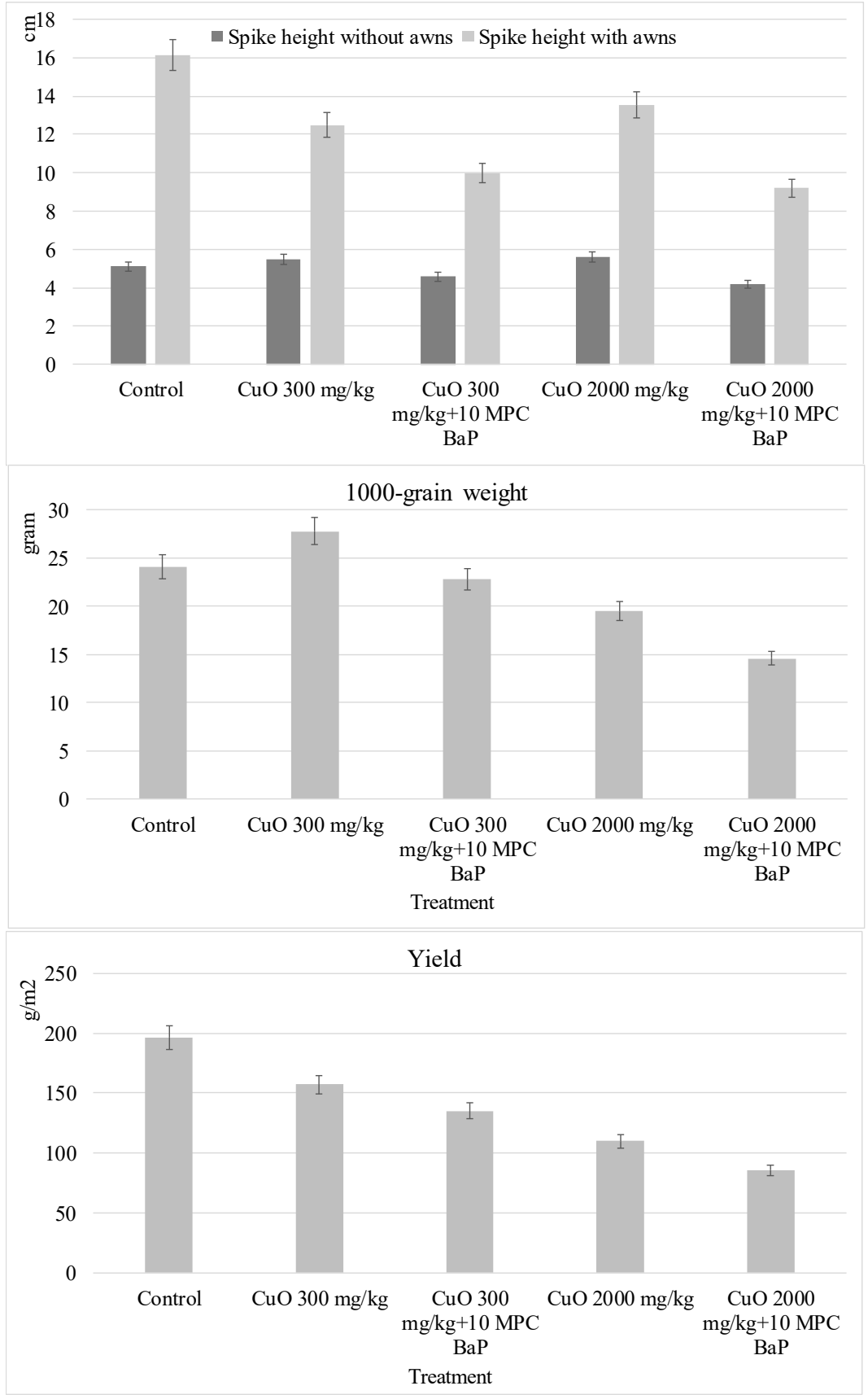


Fig. 2. Biometric parameters of two-row spring barley (Hordeum sativum distichum) in the full maturity phase.

\section{Conclusions}

The combined introduction of $\mathrm{CuO}$ and $\mathrm{BaP}$ into the soil has a negative effect on all morphobiometric parameters of barley. The most sensitive indicators of combined contamination are root length, 1000-grain weight and the yield of barley.

\section{Acknowledgements}

This research was supported by the Russian scientific foundation, no. 19-74-10046. Analytical work was carried out on the equipment of Centers for collective use of Southern Federal University "Modern microscopy" and "High Technology".

\section{References}

1. T.M. Minkina, Yu.A. Fedorov, D.G. Nevidomskaya, T.N. Pol'shina, S.S. Mandzhieva, V.A. Chaplygin, Eurasian Soil Science 50, 1033-1047 (2017)

2. Y. Sun, Q. Zhou, Y. Xu, L. Wang, X. Liang, Journal of Hazardous Materials 186, 2075-2082 (2011)

3. S. Abel, T. Nehls, B. Mekiffer, G. Wessolek, Journal of Soils and Sediments, 15, 1771-1780 (2015)

4. A.J. Frierdich, J.G. Catalano, Geochimica et Cosmochimica Acta, 91, 240-253 (2012)

5. S. Ouvrard, C. Barnier, P. Bauda, T. Beguiristain, C. Biache and others, International Journal of Phytoremediation 13, 245-263 (2011)

6. Y. Zhang, J. Liu, Y. Zhou, T. Gong, J. Wang, Y. Ge, Journal of Hazardous Materials 260, 1100-1107 (2013)

7. A.C. Agnello, M. Bagard, E.D. van Hullebusch, G. Esposito, D. Huguenot, Science of the Total Environment 563(56), 693-703 (2016)

8. K. Farrag, N. Senesi, P. Soler Rovira, G. Brunetti, Environmental Monitoring and Assessment, 184, 6593-6606 (2012)

9. R. Vácha, J. Skála, J. Čechmánková, V. Horváthová, J. Hladík, Journal of Soils and Sediments 15, 1813-1824 (2015)

10. W. Zhang, Y. Wu, M.O. Simonnot, Pedosphere 22, 434-455 (2012)

11. T.M. Minkina, V.G. Linnik, D.G. Nevidomskaya, T.V. Bauer, S.S. Mandzhieva, V.Y. Khoroshavin, Journal of Soils and Sediments 18, 2217-2228 (2018)

12. S. Sushkova, T. Minkina, I. Deryabkina (Turina), S. Mandzhieva, I. Zamulina, T. Bauer, G. Vasilyeva, E. Antonenko, V. Rajput, Journal of Soils and Sediments 18(6), 2368-2378 (2018)

13. S. Sushkova, T. Minkina, I. Deryabkina (Turina), E. Antonenko, S. Mandzhieva, I. Zamulina, T. Bauer, N. Gromakova, G. Vasilyeva, Polycyclic Aromatic Compounds 39, 395-403 (2019)

14. T. Minkina, V. Rajput, G. Fedorenko, A. Fedorenko, S. Mandzhieva, S. Sushkova, T. Morin, J. Yao, Environmental Geochemistry and Health 42(1), 45-58 (2020) DOI: 10.1007/s10653-019-00269-8

15. M.J. Gutiérrez-Ginés, A.J. Hernández, M.I. Pérez-Leblic, J. Pastor, J. Vangronsveld, 
Journal of Environmental Management 143, 197-207 (2014) 